\title{
Assembly of Anion-controlled Cadmium (II) Coordination Polymers From the Use of 2-acetyl-pyridyl-isonicotinoylhydrazone
}

F. A. Afkhami, ${ }^{a}$ A. A. Khandar, ${ }^{a,}{ }^{,}$J. M. White, ${ }^{b}$ A. Guerri, ${ }^{c}$ A. Ienco, ${ }^{d}$ J. T. Bryant, ${ }^{e}$ N. Mhesn, ${ }^{e}$ and C. Lampropoulos ${ }^{\mathrm{e}, *}$

\footnotetext{
a. Department of Inorganic Chemistry, Faculty of Chemistry, University of Tabriz, Tabriz, 51666-16471, Iran.

b. School of Chemistry and BIO-21 Molecular Science and Biotechnology, University of Melbourne, Parkville, Victoria 3052, Australia.

c. Dipartimento di Chimica, Università di Firenze, Via della Lastruccia 3, 50019 Sesto Fiorentino, Firenze, Italy.

d. $\quad$ Istituto di Chimica dei Composti Organometallici, Consiglio Nazionale delle Ricerche, Via Madonna del Piano 10, 50019 Sesto Fiorentino, Firenze, Italy

e. Department of Chemistry, University of North Florida, Jacksonville, FL 32224, USA
}

\footnotetext{
* Corresponding authors E-mail addresses: akhandar@yahoo.com (A. A. Khandar), C.Lampropoulos@unf.edu (C. Lampropoulos).
} 


\section{Abstract}

Four Cd(II) coordination polymers have been synthesized, utilizing a tetradentate pyridine-based Schiff base ligand, namely 2-acetyl-pyridyl-isonicotinoylhydrazone (HL), and different anions $\left(\mathrm{CH}_{3} \mathrm{COO}^{-}, \mathrm{N}_{3}^{-}, \mathrm{SCN}^{-}\right)$. The products $\left\{\left[\mathrm{Cd}_{2}(\mathrm{~L})_{2}\left(\mathrm{CH}_{3} \mathrm{COO}\right)_{2}\right] \cdot \mathrm{C}_{2} \mathrm{H}_{5} \mathrm{OH}\right\}_{n}(\mathbf{1})$, $\left\{\left[\mathrm{Cd}_{1.5}(\mathrm{~L})\left(\mathrm{CH}_{3} \mathrm{COO}\right)\left(\mathrm{N}_{3}\right)\left(\mathrm{H}_{2} \mathrm{O}\right)\right] \cdot \mathrm{C}_{2} \mathrm{H}_{5} \mathrm{OH}\right\}_{\mathrm{n}} \quad(\mathbf{2}), \quad\left\{\left[\mathrm{Cd}(\mathrm{HL})(\mathrm{SCN})_{2}\right] \cdot \mathrm{CH}_{3} \mathrm{OH}\right\}_{\mathrm{n}} \quad(3) \quad$ and $\left[\mathrm{Cd}_{3}(\mathrm{HL})_{2}(\mathrm{SCN})_{6}\right]_{\mathrm{n}} \quad(4)$, were characterized with single-crystal X-ray diffraction, IR spectroscopy, and luminescence studies. The ligand in $\mathbf{1}$ and $\mathbf{2}$ is singly-deprotonated and coordinates to the cadmium centre in the enolic form $(=\mathrm{N}-\mathrm{N}=\mathrm{C}-\mathrm{O})$ while in compounds 3 and 4 it coordinates in its neutral keto form $(=\mathrm{N}-\mathrm{NH}-\mathrm{C}=\mathrm{O})$. The tetradentate ligand in $\mathbf{2}$ acts as a linker and leads to the formation of a one-dimensional coordination polymer. The $\mathrm{CH}_{3} \mathrm{COO}^{-}$in $\mathbf{1}$ and $\mathrm{SCN}^{-}$in $\mathbf{3}$ and $\mathbf{4}$, further act as bridges, forming two-dimensional coordination polymers ( $\mathbf{1}$ and 3) and a three-dimensional network (4). Structural diversity is thus induced by the anions, due to the variable steric hindrance they impose as well as differing bridging capacity; metal-organic network formation is also evident via different Van der Waals forces.

\section{Introduction}

The rapidly growing field of crystal engineering of one, two-, and threedimensional (1D, 2D, 3D) coordination polymers (CPs) has been attractive, not only for their structural and topological diversities ${ }^{1-3}$ but also for their potential application as functional materials in catalysis, ${ }^{4,5}$ optics, ${ }^{6,7}$ magnetism, ${ }^{8-10}$ molecular architectures, ${ }^{11}$ materials chemistry, etc. ${ }^{12}$ However, control of the complex structures in hydro- / solvothermal reactions remains a challenge, owing to the fact that the assembly of such complexes can be easily influenced by the geometrical and electronic properties of metal ions and ligands, the temperature, as well as the $\mathrm{pH}$ of the solution. ${ }^{13-16}$ Among the factors in the design of CPs, the counterion dependence has been actively investigated, due to a) the co-ligand effects these ions exhibit, and b) their ability to direct and/or template the formation of diverse assemblies. ${ }^{17-20}$ Furthermore, counterions such as carboxylate, nitrate, azide and thiocyanate exhibit different coordination modes (monodentate, chelate, and/or bridging) within the framework, which may further enrich the structural diversity. ${ }^{20}$ Therefore, using organic/inorganic anions in the assembly of new functional materials has become a rapidly emerging field. ${ }^{21-23}$ 
On the other hand, to meet the requirement of metal-ligand binding preference and the energetic consideration of overall crystal packing, a mixed-ligand assembling strategy was proven an effective approach. A variety of organic ligands, especially polycarboxylate, polyalcohols, and polypyridyl types, have been generally regarded as the most familiar and reliable candidates to construct the desired coordination architectures in recent years. ${ }^{24-29}$ Another class of flexible and versatile polydentate ligands are hydrazones, which show very high efficiency at chelating transition metal ions. ${ }^{30}$ Hydrazones obtained from 4-pyridine carboxylic acid hydrazide can act as ditopic ligands via two different donor sites (a tridentate coordination pocket and a $\mathrm{N}$-donor pyridine moiety); this makes them excellent ligand candidates for the formation of mono- and multinuclear structures. ${ }^{31-33}$

The $\mathrm{Cd}(\mathrm{II})$ ion with its $\mathrm{d}^{10}$ electronic configuration exhibits great flexibility in its coordination environment/geometry. ${ }^{34}$ In the literature, reports of the anion effect on the coordination mode of $\mathrm{Cd}$ (II) have been rare, ${ }^{35}$ and in this context, we used the potentially tetradentate ligand, 2-acetyl-pyridyl-isonicotinoylhydrazone (HL, Scheme 1) in a systematic investigation of the anion dependence of self-assembled Cd(II) CPs. The HL ligand has the potential to form different types of complexes due to the multiple coordination sites and the potential to adopt either enol and keto tautomeric forms (Scheme 1). ${ }^{36-38}$ From this systematic investigation, we report the synthesis and characterization of four different coordination polymers, exemplifying that diversity of anions may cause major changes in the resulting structures, which in turn is of interest in the design and construction of CPs.

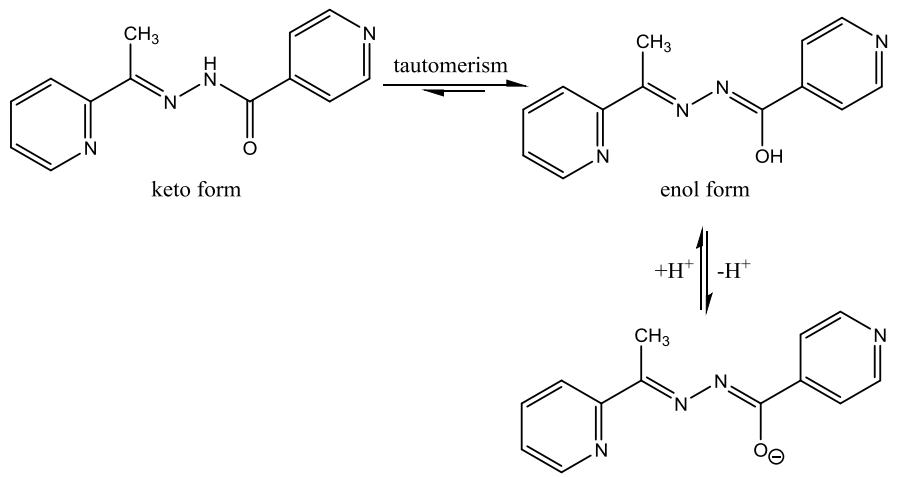

Scheme 1. Structure, keto-enol tautomerism and reversible deprotonation of 2-acetyl-pyridylisonicotinoylhydrazone (HL) 


\section{Experimental}

\subsection{Materials and Measurements}

All reagents were obtained from commercial sources and were used as received. The ligand HL was prepared as described previously. ${ }^{37}$ In short, pure HL was obtained in $>80 \%$ yield by the condensation of 2-acetylpyridine and isonicotinohydrazide in $\mathrm{EtOH}$. Selected IR bands $\left(\mathrm{KBr}\right.$ pellet, $\left.\mathrm{cm}^{-1}\right)$ : $3290(\mathrm{~N}-\mathrm{H}), 1667(\mathrm{C}=\mathrm{O})$. The branched tube method for synthesis is described detail in our previous reports. ${ }^{39}$

Elemental analyses were carried out using an Elementar Vario EL III instrument and FT-IR spectra were recorded on a Bruker Tensor 27 FT-IR spectrometer with $\mathrm{KBr}$ pellets in the range $4000-400 \mathrm{~cm}^{-1}$. Solid-state photoluminescence studies were performed at the University of North Florida, using a Photon Technology International Quanta Master 30 spectrofluorometer equipped with a xenon flash lamp having a pulse width of about $2 \mu$ s and a photomultiplier tube. The flash lamp was kept operating at a frequency of $125 \mathrm{~Hz}$ with the total period of data collection set to $8 \mathrm{~ms}$. The step size used for the spectral acquisitions was $1 \mathrm{~nm}$. The samples were mounted using a home-built solid sample holder at an angle of $40^{\circ}$ with particular attention given to keep conditions constant during experiments; all data reported are background corrected.

\subsection{Syntheses}

2.2.1 $\left\{\left[\mathrm{Cd}_{2}(\mathrm{~L})_{2}\left(\mathrm{CH}_{3} \mathrm{COO}\right)_{2}\right] \cdot \mathrm{C}_{2} \mathrm{H}_{5} \mathrm{OH}\right\}_{\mathrm{n}}(\mathbf{1})$. To a stirred solution of $\mathrm{HL}(0.120 \mathrm{~g}, 0.5 \mathrm{mmol})$ in ethanol, was added an aqueous solution of $\mathrm{Cd}\left(\mathrm{CH}_{3} \mathrm{COO}\right)_{2} \cdot 2 \mathrm{H}_{2} \mathrm{O}(0.130 \mathrm{~g}, 0.5 \mathrm{mmol})$ in small portions. The resulting reaction mixture was briefly stirred, and then left unperturbed. After 2 days, yellow crystals of 1 were obtained. Yield: 55\%. Anal. Calc. for $\mathrm{C}_{32} \mathrm{H}_{34} \mathrm{Cd}_{2} \mathrm{~N}_{8} \mathrm{O}_{7}$ : C, 44.31; H, 3.95; N, 12.91. Found: C, 44.53; H, 3.99; N, 13.06\%. IR $\left(\mathrm{KBr}\right.$ pellet, $\left.\mathrm{cm}^{-1}\right)$ selected bands: $3078,1605,1568,1517,1465,1418,1360,1307,1162$, 1097, 1041, 916, 853, 789, 763, 694.

2.2.2 $\left\{\left[\mathrm{Cd}_{1.5}(\mathrm{~L})\left(\mathrm{CH}_{3} \mathbf{C O O}\right)\left(\mathbf{N}_{3}\right)\left(\mathbf{H}_{2} \mathbf{O}\right)\right] \cdot \mathbf{C}_{2} \mathbf{H}_{5} \mathrm{OH}\right\}_{\mathrm{n}}$ (2). To a stirred solution of HL $(0.120 \mathrm{~g}$, $0.5 \mathrm{mmol})$ in ethanol, was added an aqueous solution of $\mathrm{Cd}\left(\mathrm{CH}_{3} \mathrm{COO}\right)_{2} \cdot 2 \mathrm{H}_{2} \mathrm{O}(0.130 \mathrm{~g}$, $0.5 \mathrm{mmol})$ in small portions, as well as $\mathrm{NaN}_{3}(0.065 \mathrm{~g}, 1.0 \mathrm{mmol})$. The reaction mixture was briefly stirred and then left undisturbed. After 3 days, yellow crystals of 2 were 
obtained. Yield: 59\%. Anal. Calc. for $\mathrm{C}_{17} \mathrm{H}_{22} \mathrm{Cd}_{1.5} \mathrm{~N}_{7} \mathrm{O}_{5}: \mathrm{C}, 35.63 ; \mathrm{H}, 3.87 ; \mathrm{N}, 17.11$. Found: C, 35.73; H, 3.97; N, 17.04\%. IR (KBr pellet, $\mathrm{cm}^{-1}$ ) selected bands: 2973, 2062, 1601, 1564, 1506, 1460, 1413, 1356, 1255, 1163, 1094, 1050, 916, 857, 774, 700.

2.2.3 $\left\{\left[\mathrm{Cd}(\mathrm{HL})(\mathrm{SCN})_{2}\right] \cdot \mathrm{CH}_{3} \mathrm{OH}\right\}_{\mathrm{n}}(3)$ and $\left[\mathrm{Cd}_{3}(\mathrm{HL})_{2}(\mathrm{SCN})_{6}\right]_{\mathbf{n}}(4)$. In the main arm of a branched tube were added $\mathrm{HL}(0.120 \mathrm{~g}, 0.5 \mathrm{mmol})$ and $\mathrm{Cd}\left(\mathrm{NO}_{3}\right)_{2} \bullet 4 \mathrm{H}_{2} \mathrm{O}(0.154 \mathrm{~g}, 0.5$ mmol). Methanol was carefully added to fill the arms; ammonium thiocyanate (0.076 g, $1.0 \mathrm{mmol}$ ) was added to the mixture as well. The reaction tube was sealed, and immersed in an oil bath at $60{ }^{\circ} \mathrm{C}$ while the branched arm was kept at ambient temperature; the vessel remained immersed in the oil bath for a total of 3 days. After $24 \mathrm{~h}$ of heating, in the cooler arm of the apparatus, yellow crystals of $\mathbf{3}$ formed, while after $72 \mathrm{~h}$ a second product emerged as colourless single crystals of 4. Compound 3: Yield: 53\%. Anal. Calc. for $\mathrm{C}_{16} \mathrm{H}_{16} \mathrm{CdN}_{6} \mathrm{O}_{2} \mathrm{~S}_{2}$ : C, 38.37; H, 3.22; N, 16.78. Found: C, 38.24; H, 3.21; N, $16.69 \%$. IR ( $\mathrm{KBr}$ pellet, $\mathrm{cm}^{-1}$ ) selected bands: 3313, 3062, 2097, 1661, 1511, 1451, 1375, 1284 , 1240, 1165, 1047, 926, 836, 753, 693. Compound 4: Anal. Calc. for $\mathrm{C}_{32} \mathrm{H}_{22} \mathrm{Cd}_{3} \mathrm{~N}_{14} \mathrm{O}_{2} \mathrm{~S}_{6}$ : C, 33.01; H, 1.90; N, 16.84. Found: C, 32.84; H, 2.10; N, 16.81\%. IR ( $\mathrm{KBr}$ pellet, $\left.\mathrm{cm}^{-1}\right)$ selected bands: 3264, 2120, 2051, 1668, 1505, 1467, 1430, 1371, 1292, 1248, 1166, 1097 , $1045,912,780,746,700$.

\subsection{Structure Determination}

Intensity data on single crystals suitable for X-ray analyses were collected on an Oxford Diffraction Super Nova diffractometer, using Mo Ka radiation $(\lambda=0.71073 \AA)$ at $150 \mathrm{~K}$ for compound 1. The data sets for compounds 2-4 were collected on an Oxford Diffraction Super Nova diffractometer using graphite-monochromated $\mathrm{Cu} \mathrm{K \alpha}$ radiation $(\lambda=1.5418 \AA)$ at $130 \mathrm{~K}$ (Table1). The structures were determined by direct methods and refined by full-matrix leastsquares procedures using the SHELXTL. ${ }^{40}$ All the hydrogen atoms were fixed in calculated positions. The molecular structure plots were prepared by using ORTEPIII ${ }^{41}$ and Mercury. ${ }^{42}$ The details of the crystal parameters, data collection and refinements for the complexes are summarized in Table 1. Selected bond lengths and angles are listed in Table S1-S4. 
Table 1. Crystal data and structure refinements for compounds 1-4

\begin{tabular}{|c|c|c|c|c|}
\hline Compound & 1 & 2 & 3 & 4 \\
\hline Formula & $\mathrm{C}_{32} \mathrm{H}_{34} \mathrm{Cd}_{2} \mathrm{~N}_{8} \mathrm{O}_{7}$ & $\mathrm{C}_{17} \mathrm{H}_{22} \mathrm{Cd}_{1.5} \mathrm{~N}_{7} \mathrm{O}_{5}$ & $\mathrm{C}_{16} \mathrm{H}_{16} \mathrm{CdN}_{6} \mathrm{O}_{2} \mathrm{~S}_{2}$ & $\mathrm{C}_{32} \mathrm{H}_{22} \mathrm{Cd}_{3} \mathrm{~N}_{14} \mathrm{O}_{2} \mathrm{~S}_{6}$ \\
\hline $\mathrm{F} w\left(\mathrm{~g} \mathrm{~mol}^{-1}\right)$ & 868.47 & 573.02 & 500.87 & 1164.20 \\
\hline Color & yellow & yellow & yellow & colorless \\
\hline Crystal system & monoclinic & triclinic & monoclinic & monoclinic \\
\hline Space group & $P 2_{1} / n$ & $P-1$ & $P 2_{1} / n$ & $P 2_{1} / c$ \\
\hline$a(\AA)$ & $10.3431(4)$ & $10.2669(4)$ & $12.2523(10)$ & $7.8891(2)$ \\
\hline$b(\AA)$ & $14.1172(4)$ & $10.4517(5)$ & $12.2981(7)$ & $10.8953(3)$ \\
\hline$c(\AA)$ & $23.2620(8)$ & $10.8186(5)$ & $13.6445(12)$ & $24.0656(7)$ \\
\hline$\alpha\left(^{0}\right)$ & 90.00 & $85.834(4)$ & 90.00 & 90.00 \\
\hline$\beta\left(^{\mathrm{o}}\right)$ & $97.170(4)$ & $69.924(4)$ & $112.611(10)$ & $96.765(3)$ \\
\hline$\gamma\left({ }^{\mathrm{o}}\right)$ & 90.00 & $74.549(4)$ & 90.00 & 90.00 \\
\hline$V\left(\AA^{3}\right)$ & $3370.1(2)$ & $1050.73(8)$ & $1897.9(3)$ & $2054.14(10)$ \\
\hline Temp (K) & $150(2)$ & 130(2) & $130(2)$ & 130(11) \\
\hline $\mathrm{Z}$ & 4 & 2 & 4 & 2 \\
\hline$D_{\mathrm{c}}\left(\mathrm{g} \mathrm{cm}^{-3}\right)$ & 1.706 & 1.811 & 1.753 & 1.882 \\
\hline$\mu\left(\mathrm{mm}^{-1}\right)$ & 1.321 & 1.266 & 1.149 & 1.560 \\
\hline \multirow[t]{3}{*}{ Index ranges } & $-15<h<14$ & $-8<h<12$ & $-14<h<14$ & $-9<h<9$ \\
\hline & $-18<k<20$ & $-12<k<12$ & $-11<k<14$ & $-13<k<11$ \\
\hline & $-33<l<34$ & $-12<l<12$ & $-13<l<16$ & $-29<l<22$ \\
\hline$F(000)$ & 1736 & 570 & 1000 & 1136 \\
\hline $\mathrm{R}_{\text {int }}^{\mathrm{a}}$ & 0.0450 & 0.0331 & 0.0280 & 0.0352 \\
\hline$R_{1}(\mathrm{I}>2 \sigma(\mathrm{I}))$ & 0.0738 & 0.0342 & 0.0289 & 0.0363 \\
\hline $\mathrm{w} R_{2}$ (all data) & 0.1002 & 0.0921 & 0.0741 & 0.0952 \\
\hline GOF & 1.066 & 1.074 & 1.093 & 1.073 \\
\hline
\end{tabular}

a $R_{1}=\sum\left[\left|F_{\mathrm{o}}\right|-\left|F_{\mathrm{c}}\right|\left|/ \sum\right| F_{\mathrm{o}} \mid . \mathrm{w} R_{2}=\left\{\left[\sum \mathrm{w}\left(\left|F_{\mathrm{o}}{ }^{2}-F_{\mathrm{c}}{ }^{2}\right|\right)^{2}\right] /\left[\sum \mathrm{w}\left(F_{\mathrm{o}}{ }^{2}\right)^{2}\right\}\right]^{1 / 2}, \mathrm{w}=1 /\left[\sigma^{2}\right.\right.$ $\left(F_{\mathrm{o}}{ }^{2}\right)+\left[(a p)^{2}+b p\right]$, where $p=\left[\max \left(F_{\mathrm{o}}{ }^{2}, 0\right)+2 F_{c}{ }^{2}\right] / 3$.

\section{Results and Discussion}

\subsection{Synthesis and IR Spectroscopy}

For the syntheses of $\mathbf{1}$ and $\mathbf{2}$, typical wet chemistry techniques were used, whereas for 3 and $\mathbf{4}$, the branched tube apparatus was used, as we have previously discussed in detail. $^{39}$ The velocity of the convection current is proportional to the thermal gradient across the vessel, so we were careful not to make the gradient too large because the rapid convection inhibits crystal growth. ${ }^{36}$ It is also noted here that reactions using various 
reactant ratios were performed; herein the reactions which yielded crystalline products at the highest isolated yields are reported.

The HL ligand is expected to exhibit keto-enol tautomerism, and the amido proton can be dissociated through enolization (Scheme 1). The IR spectrum of the ligand exhibits two bands in the regions 3200 and $1661 \mathrm{~cm}^{-1}$ due to $v(\mathrm{~N}-\mathrm{H})$ and $v(\mathrm{C}=\mathrm{O})$ stretches, respectively. ${ }^{37}$ The free ligand amide $\mathrm{N}-\mathrm{H}$ and $\mathrm{C}=\mathrm{O}$ stretching vibrations are not observed in the IR spectra of compounds $\mathbf{1}$ and $\mathbf{2}$, but they exhibit a strong absorption band around $1600 \mathrm{~cm}^{-1}$, which is not observed in the free ligand. The latter is due to a conjugated $\mathrm{C}=\mathrm{N}-\mathrm{N}=\mathrm{C}-\mathrm{O}^{-}$moiety; therefore in $\mathbf{1}$ and $\mathbf{2}$, the deprotonated ligand is predominantly in the enolate form. The IR spectra of $\mathbf{3}$ and $\mathbf{4}$, however, where the amide $\mathrm{N}$-atom is not deprotonated, exhibit both the amide and $\mathrm{C}=\mathrm{O}$ vibrations and there is no peak around $1600 \mathrm{~cm}^{-1}$, which is the characteristic peak of the deprotonated ligand (vide infra).

\subsection{Structure Descriptions}

3.2.1 $\left\{\left[\mathrm{Cd}_{2}(\mathrm{~L})_{2}\left(\mathrm{CH}_{3} \mathrm{COO}\right)_{2}\right] \cdot \mathrm{C}_{2} \mathrm{H}_{5} \mathrm{OH}\right\}_{\mathbf{n}}$ (1). There are two independent $\mathrm{Cd}(\mathrm{II})$ centres in this compound. As illustrated in Fig. 1, Cd1 is coordinated to six atoms, three of which are occupied by one HL ligand in the $\mathrm{N}_{2} \mathrm{O}$-donor form, while the other three positions are occupied by two acetate oxygen atoms (O5 and O10), and one oxygen from a bridging acetate group $(\mathrm{Cd} 1-\mathrm{O} 4=$ $2.195 \AA$ ), which links $\mathrm{Cd} 1$ to $\mathrm{Cd} 2$ from an adjacent unit $\left(\mathrm{Cd} 1-\mathrm{O} 4-\mathrm{Cd} 2=132.72^{\circ}\right) . \mathrm{Cd} 2$ is seven coordinated with a distorted monocapped trigonal-prismatic geometry (Fig. 1b) in which three positions are occupied by two nitrogen (N7 and N27) and one oxygen from an HL ligand (O2), while another two positions are occupied by two pyridyl $\mathrm{N}$ atoms from two different adjacent HL ligands (N4 and N5). The remaining two positions are occupied by two oxygen atoms (O3 and O4) of an acetate group $\left(\mathrm{Cd} 2-\mathrm{O} 3 / 4=2.536,2.349 \AA\right.$; $\left.\mathrm{O} 3-\mathrm{Cd} 2-\mathrm{O} 4=52.91^{\circ}\right)$. 

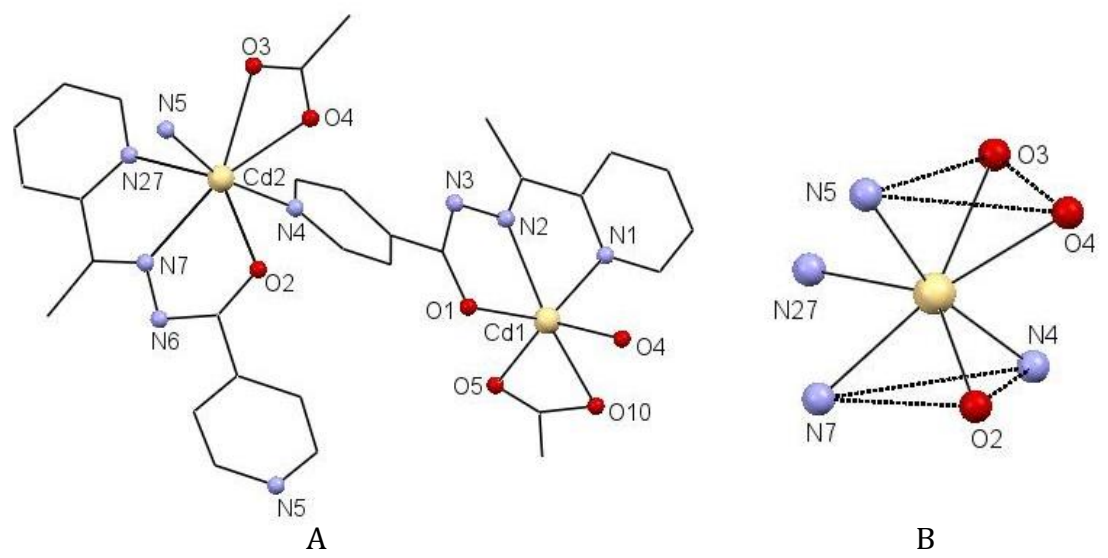

Fig. 1. (a) The partially-labeled structure of complex 1, and (b) Monocapped trigonal-prismatic geometry for $\mathrm{Cd} 2$ in $\mathbf{1}$.

In compound 1, the Schiff base ligand and an acetate group act as bridging ligands, and this compound adopts a 2D herringbone pattern network. These sheets are formed by 18membered $\left[\mathrm{Cd}_{4}(\mathrm{~L})_{2}\left(\mathrm{CH}_{3} \mathrm{COO}\right)_{2}\right]$ metallacycles, presented in Fig. 2. The uncoordinated ethanol molecules in $\mathbf{1}$ are trapped between the 2D layers and acting as hydrogen donors toward N3 (O6$\mathrm{N} 3=2.828$ ). Eventually the hydrogen bonding between adjacent molecules grow 2D layers into a three-dimensional network (vide infra). 


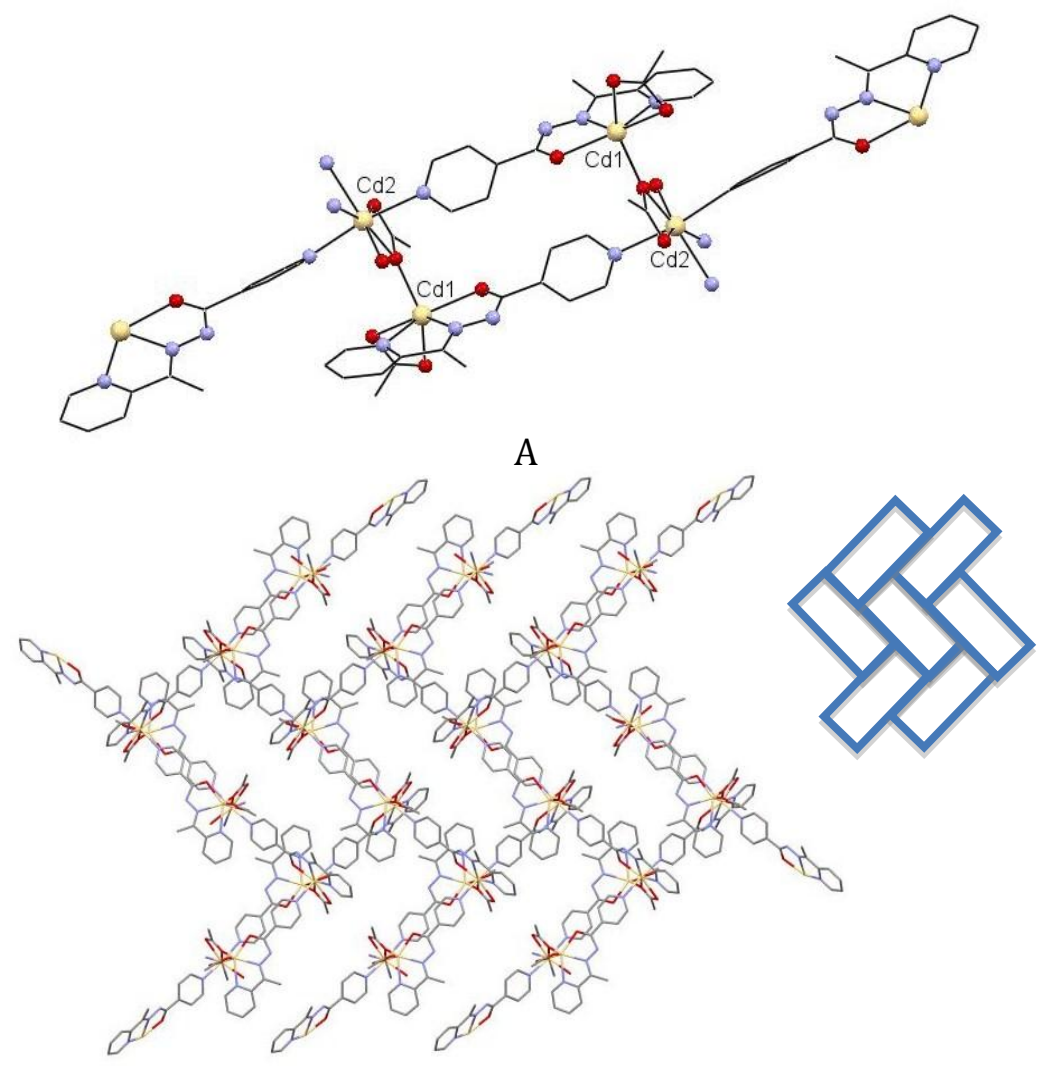

B

Fig. 2. (a) A box of tetranuclear metallacycle $\left[\mathrm{Cd}_{4}(\mathrm{~L})_{2}\left(\mathrm{CH}_{3} \mathrm{COO}\right)_{2}\right]$ and (b) Depiction of $2 \mathrm{D}$ herringbone pattern network in $\mathbf{1}$. Interstitial ethanol molecules are omitted for clarity.

3.2.2 $\left\{\left[\mathrm{Cd}_{1.5}(\mathrm{~L})\left(\mathrm{CH}_{3} \mathrm{COO}\right)\left(\mathrm{N}_{3}\right)\left(\mathrm{H}_{2} \mathrm{O}\right)\right] \cdot \mathrm{C}_{2} \mathrm{H}_{5} \mathrm{OH}\right\}_{\mathrm{n}} \quad$ (2). In this compound two crystallographically independent $\mathrm{Cd}(\mathrm{II})$ ions exhibit distorted octahedral and pentagonalbipyramidal geometries (Fig. 3). Cd2 is coordinated by seven atoms, in which three positions are occupied by the $\mathrm{HL}$ ligand in the $\mathrm{N}_{2} \mathrm{O}$-donor form, two positions are occupied from two oxygen atoms from one, which links two adjacent metal ions (Cd1$\mathrm{O} 2-\mathrm{Cd} 2=99.03^{\circ}$ ), one position is occupied from one oxygen of a water molecule, and one position coming from the azide ligand. The latter links two adjacent $\mathrm{Cd}(\mathrm{II})$ ions in the end-on $\mu-1,1$ mode $\left(\mathrm{Cd} 1-\mathrm{N}-\mathrm{Cd} 2=104.60^{\circ}\right)$. On the other hand each $\mathrm{Cd} 1$ ion is coordinated by two para-N atoms from the two different $\mathrm{L}^{-1}$ ligands, in a transdisposition, and by two oxygen atoms from two different acetates, also in a transdisposition. Finally, the coordination sphere of Cd1 is completed by two different azide ligands, which link $\mathrm{Cd} 1$ to $\mathrm{Cd} 2$ in the $\mu-1,1$ end-on mode $(\mathrm{Cd} 1-\mathrm{N} 21=2.25 \AA)$. 


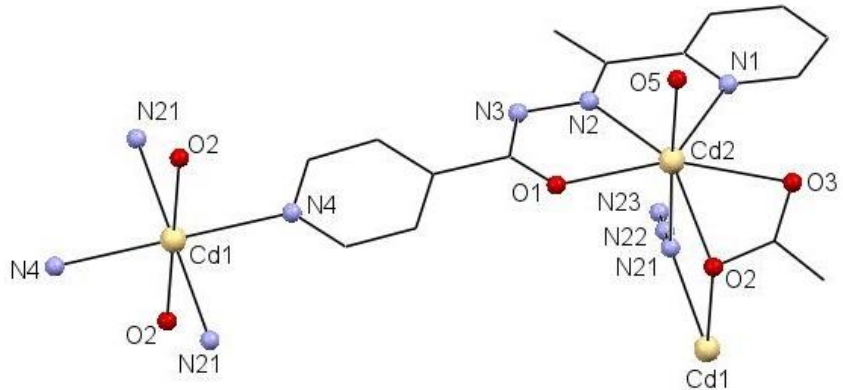

A

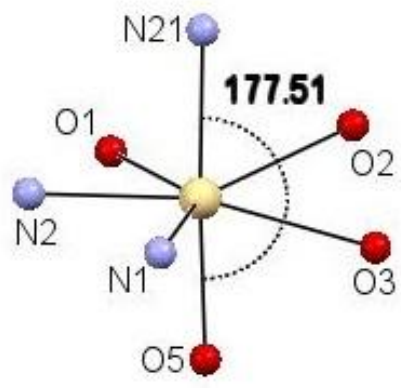

B

Fig. 3. (a) A view of $\mathrm{Cd} 1$ and $\mathrm{Cd} 2$ coordination environments and (b) pentagonal-bipyramidal geometry for $\mathrm{Cd} 2$ centre in $\mathbf{2}$.

Due to the coorindating ligand disposition, namely the Schiff base ligand groups being directly across acetate and azide bridges, the structure of 2 resembles a 1D ladder chain. The chain's links are formed by 18-membered $\left[\mathrm{Cd}_{4}(\mathrm{~L})_{2}\left(\mathrm{CH}_{3} \mathrm{COO}\right)_{2}\left(\mathrm{~N}_{3}\right)_{2}\right]$ metallacycles, represented in Fig. 4. Hydrogen bonds allow the individual metallacycle units in 2 to interact $(\mathrm{O} 3 \ldots \mathrm{O} 5=2.74 \AA / \mathrm{OH} \ldots \mathrm{O} 3$ acetate $=1.83 \AA)$, thus creating the supramolecular ladder-type motif. In the asymmetric unit, there is also an ethanol molecule which is hydrogen bonded to the enol-oxygen of the Sciff base ligand. In the packing diagram it can be seen that adjacent chains are closely packed in the crystal lattice, with the interstitial ethanols mediating a weak hydrogen bonding interaction between them (vide infra). 


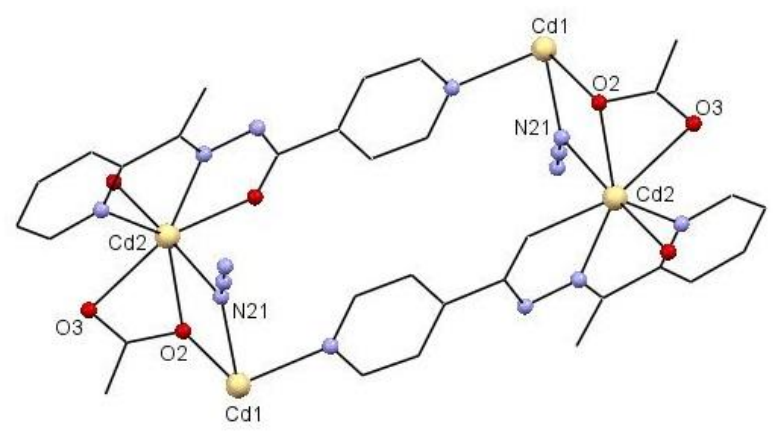

A
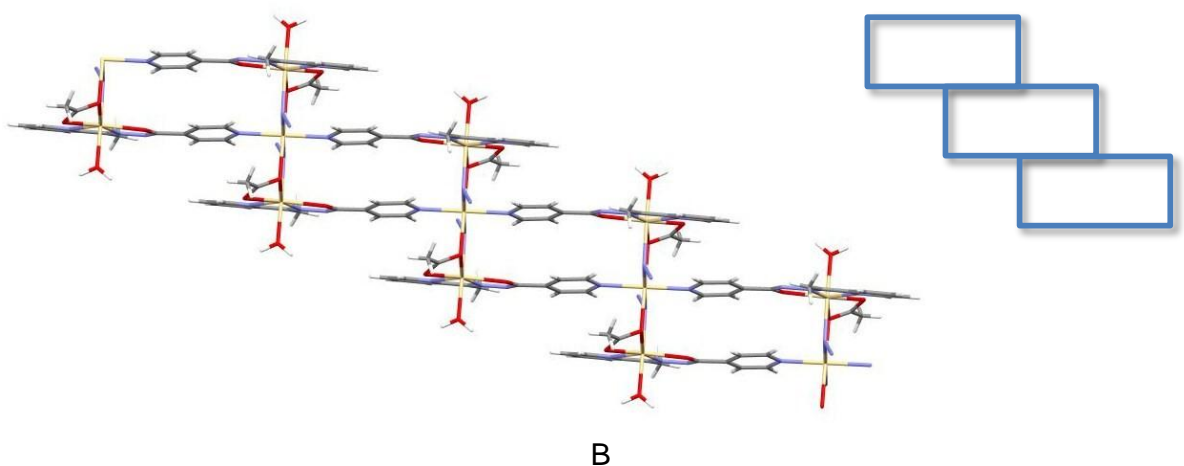

Fig. 4. (a) The partially labelled tetranuclear metallacycle $\left[\mathrm{Cd}_{4}(\mathrm{~L})_{2}\left(\mathrm{CH}_{3} \mathrm{COO}\right)_{2}\left(\mathrm{~N}_{3}\right)_{2}\right]$ in 2 , and (b) Depiction of 1D ladder chain in 2. Interstitial ethanol molecules are omitted for clarity.

3.2.3 $\left\{\left[\mathbf{C d}(\mathbf{H L})(\mathbf{S C N})_{2}\right] \cdot \mathrm{CH}_{3} \mathrm{OH}\right\}_{\mathbf{n}}$ (3). The major product of the reaction of HL with $\mathrm{Cd}\left(\mathrm{NO}_{3}\right)_{2}$ in the presence of $\mathrm{NH}_{4} \mathrm{SCN}$ was compound 3. In this compound each $\mathrm{Cd}(\mathrm{II})$ centre is seven coordinated with a distorted pentagonal-bipyramidal geometry (Fig. 5) in which four coordination sites are occupied by two different HL ligands and three other positions are occupied by three different thiocyanate ligands. One of the $\mathrm{SCN}^{-}$ligands acts as a terminal group bonded via the $\mathrm{S}$ atom to the metal centres with $\mathrm{Cd} 1-\mathrm{S} 2$ bond length of $2.69 \AA$. The other two $\mathrm{SCN}^{-}$ligands form a full bridge to a cadmium atom of an adjacent $(\mathrm{SCN})_{2}-\mathrm{Cd}-\mathrm{L}$ moiety, building doubly $\mathrm{Cd}-(\mathrm{SCN})-\mathrm{Cd}$ bridged units as shown in Fig. 5. In compound 3, the tetradentate Schiff base ligand and two thiocyanate groups act as bridging ligands, and this compound is thus described as a $2 \mathrm{D}$ network featuring a brick wall or herringbone-like motif (Fig. 5C). Each "brick" in this herringbone pattern $2 \mathrm{D}$ network is a $\left[\mathrm{Cd}_{6}(\mathrm{HL})_{6}(\mathrm{SCN})_{12}\right]$ metallacycle containing 6 asymmetric units. In addition, each assymetric unit contains an methanol molecule, which mediates two hydrogen bonds to two 2D sheets of metallacycles $(\mathrm{N} 6-\mathrm{O} 2=2.75 \AA$ and $\mathrm{N} 3-\mathrm{O} 2=2.83$ $\AA$ ). This leads to the formation of a supramolecular 3D network made of 2D herringbone pattern sheets, linked via hydrogen bonds through interstitial methanols (vide infra). 

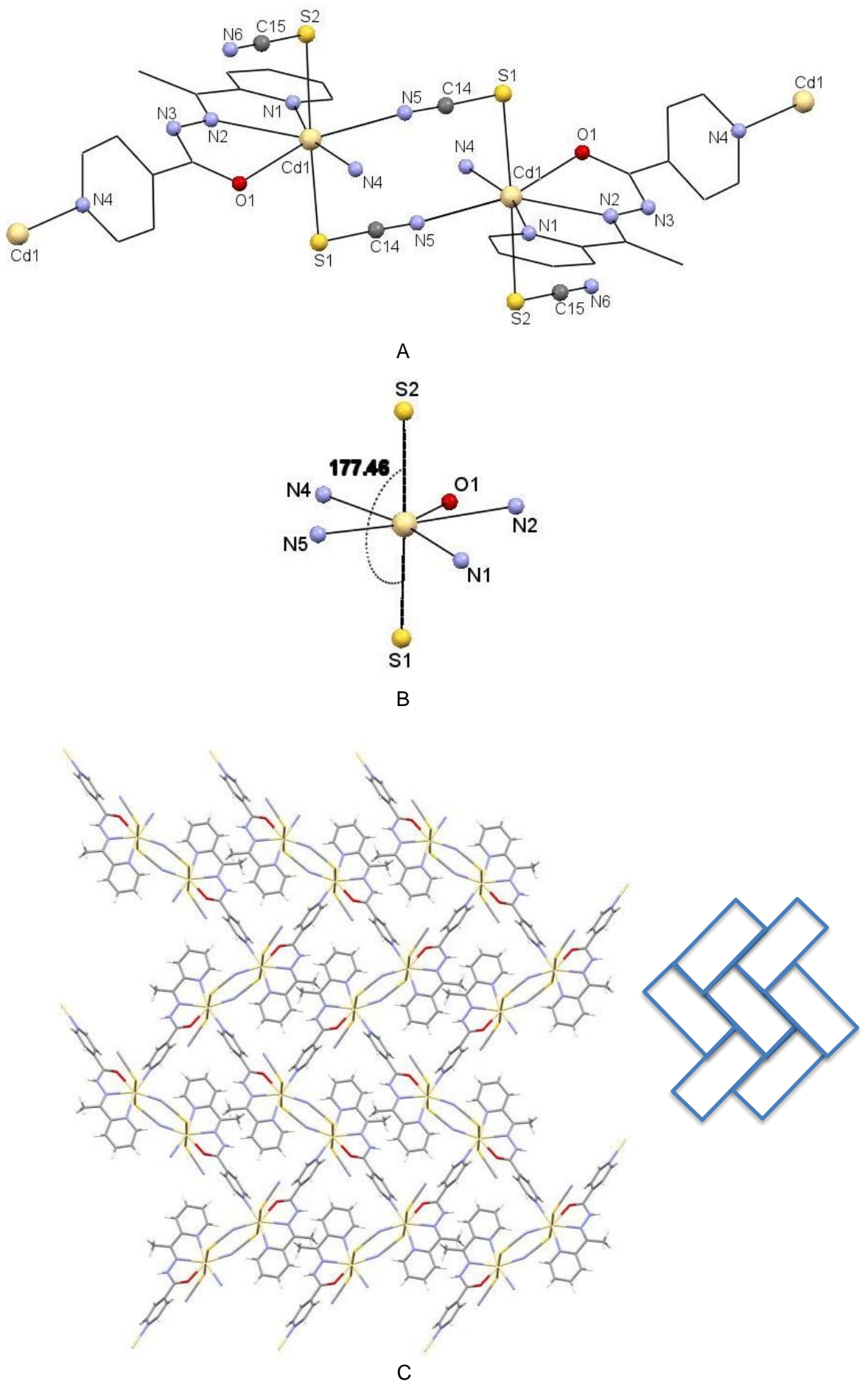

Fig. 5. (a) The partially labelled crystal structure of 3, shown as a dimer to emphasize the doubly-bridged topology, (b) the pentagonal-bipyramidal geometry for $\mathrm{Cd}$ in $\mathbf{3}$, and (c) the 2D herringbone pattern network in $\mathbf{3}$. Interstitial methanol molecules are omitted for clarity. 
3.2.4 $\left[\mathrm{Cd}_{3}(\mathrm{HL})_{2}(\mathrm{SCN})_{6}\right]_{\mathbf{n}}(4)$. This compound was the second product of the reaction of HL with $\mathrm{Cd}\left(\mathrm{NO}_{3}\right)_{2} \cdot 4 \mathrm{H}_{2} \mathrm{O}$ in the presence of $\mathrm{NH}_{4} \mathrm{SCN}$. In 4 each $\mathrm{Cd}(\mathrm{II})$ centre is sixcoordinate and there are two crystallographically independent $\mathrm{Cd}(\mathrm{II})$ centres as shown in Fig. 6A. Cd1 is coordinated by one $\mathrm{N}_{2} \mathrm{O}$-donor $\mathrm{HL}$ ligand and by a pyridyl para- $\mathrm{N}$ of an adjacent HL ligand, in addition to two sulfur atoms of the two different thiocyanate ligands. One of the $\mathrm{SCN}^{-}$ligands links two adjacent $\mathrm{Cd} 1$ ions in the $\mu-1,3$ mode and the other $\mathrm{SCN}^{-}$ligand links $\mathrm{Cd} 1$ and $\mathrm{Cd} 2$ ions in the same mode. Each $\mathrm{Cd} 2$ centre is coordinated by two pyridyl para-N atoms from two different HL ligands in a trans disposition, and by four different $\mathrm{SCN}^{-}$ligands, of which two are bridging (vide supra) and the other two are terminal, bound via their $\mathrm{N}$ atoms $(\mathrm{Cd} 2-\mathrm{N} 7=2.30 \AA)$. This compound has a 3D network as shown in Fig. 6B.

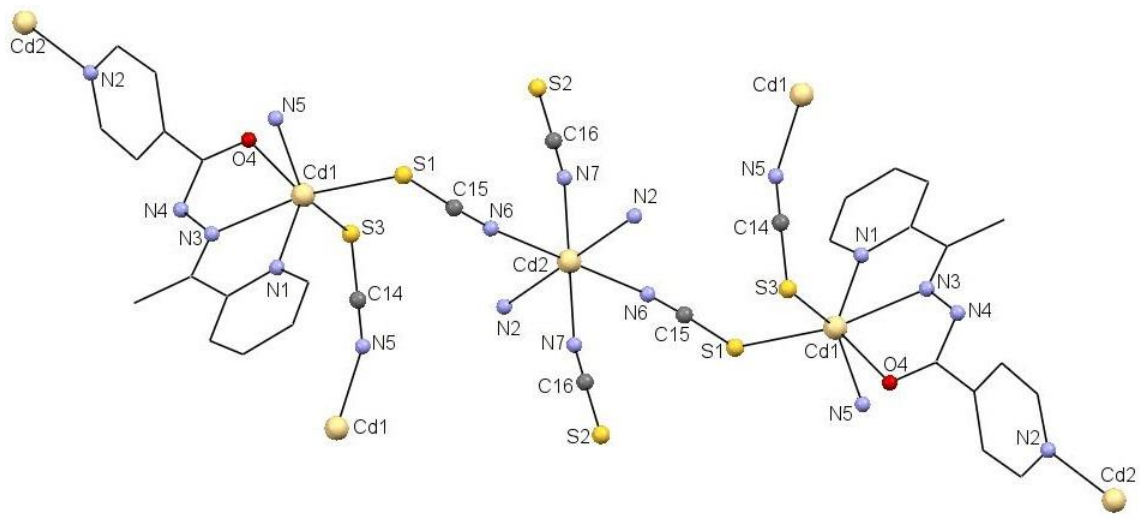

A

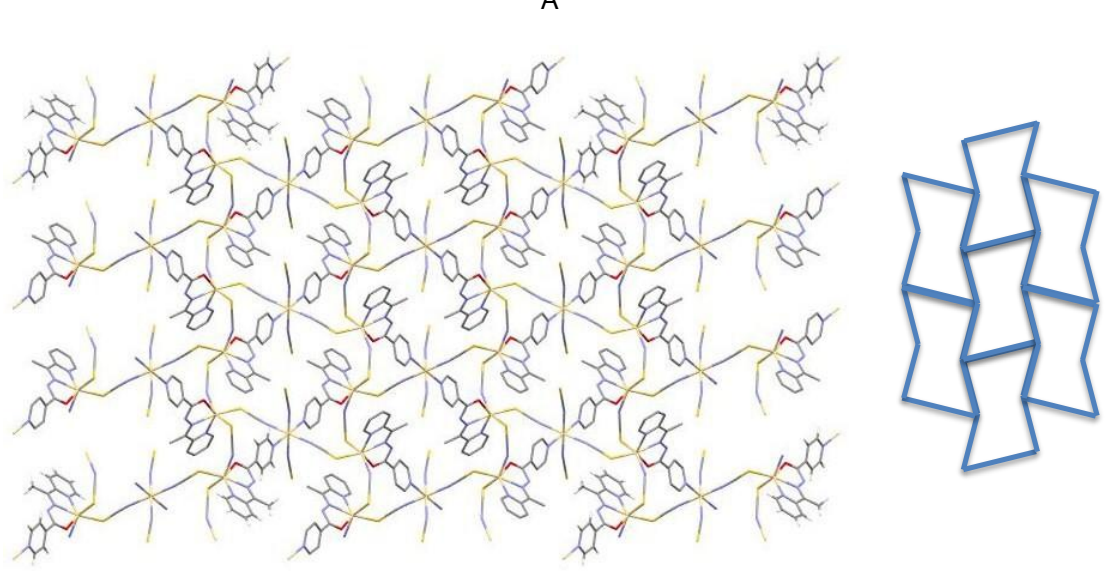

B

Fig. 6. a) The partially labelled crystal structure of $\mathbf{4}$, showing the $\mathrm{Cd} 1$ and $\mathrm{Cd} 2$ coordination environments, and b) the 3D network in 4.

\subsection{Comparison of the structures}


There are some major similarities between the structures of 1-4. In all compounds three coordination positions of $\mathrm{Cd}(\mathrm{II})$ are occupied by the ortho- $\mathrm{N}$ of the pyridyl group, the imine nitrogen and the oxygen of the Schiff base ligand. In all compounds at least one para-N of a pyridyl group of the adjacent molecule coordinates to the $\mathrm{Cd}(\mathrm{II})$ centre and the Schiff base ligand acts as chelating-bridging agent. In compounds $\mathbf{1}$ and $\mathbf{2}$ the oxygen atom of the Schiff base coordinates to the $\mathrm{Cd}(\mathrm{II})$ centre in the form of enolate, but in $\mathbf{3}$ and $\mathbf{4}$ it coordinates as the neutral keto form (Scheme 2).

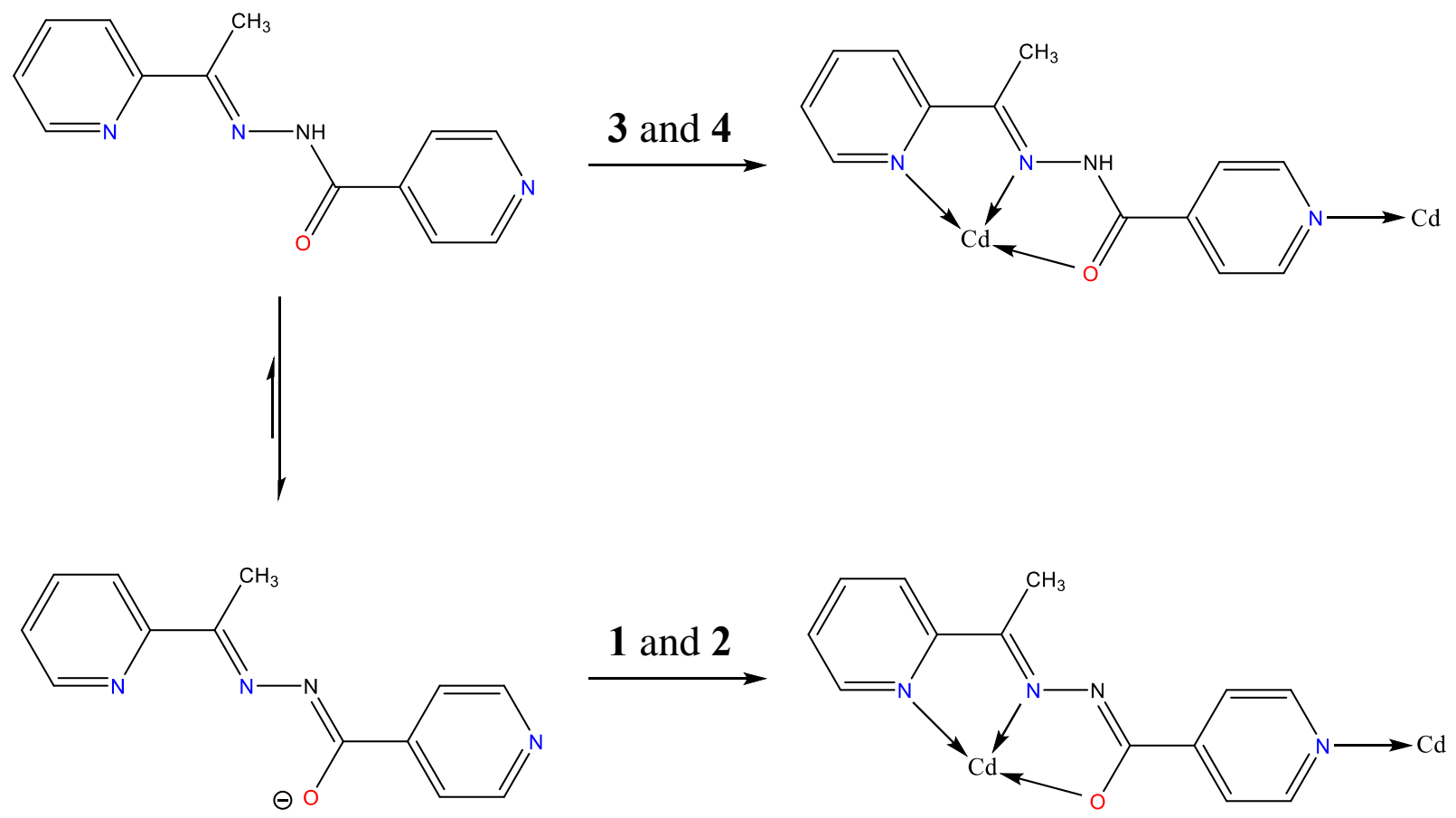

Scheme 2. The binding mode of 2-acetyl-pyridyl-isonicotinoylhydrazone (HL) in complexes 1-4

As shown in Scheme 2 the pyridyl para-N plays a major role in the design and construction of coordination polymers, while the ancillary ligands greatly influence the coordination geometry around the metal centres. Bridging by the pyridine-based ligand causes compound $\mathbf{2}$ to form one-dimensional ladder-like polymers where the metal centres are connected to each other by pyridyl para-N. The versatile acetate anion in $\mathbf{1}$, and ambidentate thiocyanate in $\mathbf{3}$ act as metal ion bridges and thus form 2D brick-wall coordination polymers. Interestingly, bridging by $\mathrm{HL}$ and $\mathrm{SCN}^{-}$also leads to the threedimensional metal-organic network in 4. 
Complexes 1-3 form supramolecular 3D networks via hydrogen bonding interactions (Table 2). These interactions are facilitated by trapped solvent molecules in-between the metal complex layers (ethanol in $\mathbf{1}$ and 2, and methanol in 3), as seen in Figs. S1-S3. Evacuation of the interlayer space and accurate measurement of the intermolecular space was beyond the scope of this work. However, as it is evident from the donor-acceptor distances in Table 2, the host-guest interactions between layers are significant.

Table 2. Intermolecular hydrogen bonds in the crystal structures of complexes $\mathbf{1}-\mathbf{3}(\mathrm{A}=$ acceptor, $\mathrm{D}=$ donor $^{a}$

\begin{tabular}{ccccc}
\hline Interaction & $\mathrm{D}-\mathrm{H}$ & $\mathrm{H} \ldots \mathrm{A}(\AA)$ & $\mathrm{D} \ldots \mathrm{A}(\AA)$ & $\mathrm{D}-\mathrm{H} \ldots \mathrm{A}\left({ }^{0}\right)$ \\
\hline Complex 1 & & & & \\
$\mathrm{O}(6)-\mathrm{H}(6) \ldots \mathrm{N}(3)$ & 0.840 & 2.009 & 2.828 & 164.71 \\
Complex 2 & & & & \\
$\mathrm{O}(5)-\mathrm{H}(5 \mathrm{~B}) \ldots \mathrm{O}(3)$ & 0.930 & 1.832 & 2.743 & 165.68 \\
& & & & \\
Complex 3 & & & & \\
$\mathrm{N}(3)-\mathrm{H}(3) \ldots \mathrm{O}(2)$ & 0.860 & 1.980 & 2.834 & 172.35 \\
$\mathrm{O}(2)-\mathrm{H}(2) \ldots \mathrm{N}(6)$ & 0.820 & 1.954 & 2.755 & 165.45 \\
\hline
\end{tabular}

${ }^{a}$ There is no significant hydrogen bonding in complex 4 (3D network).

\subsection{Photoluminescence Study}

In order to investigate the effect of ancillary ligands in the photophysics of complexes 1 4, the photoluminescence properties of the free Schiff-base ligand HL and the coordination compounds $(\mathbf{1}-\mathbf{4})$ were studied in the solid state at room temperature $(298 \mathrm{~K})$. The spectral patterns shown in Fig. 7 all correspond to an excitation wavelength $\lambda_{\mathrm{ex}}=365 \mathrm{~nm}$. The photoluminescence emission patterns of the coordination complexes are very similar to that of the free ligand, indicative of intramolecular transitions. The decrease in emission intensity of complexes $1-4$ with respect to the free ligand HL can be attributed to a quenching effect of the $\mathrm{N}_{3}^{-}, \mathrm{CH}_{3} \mathrm{COO}^{-}$, and $\mathrm{SCN}^{-}$ligands. The different coordination environments of the metal ions, and/or the non-covalent interactions leading to supramolecular networks (vide supra) could also affect the emission intensity as well as the wavelength, and as such the spectral patterns often appear different than the free ligand. 


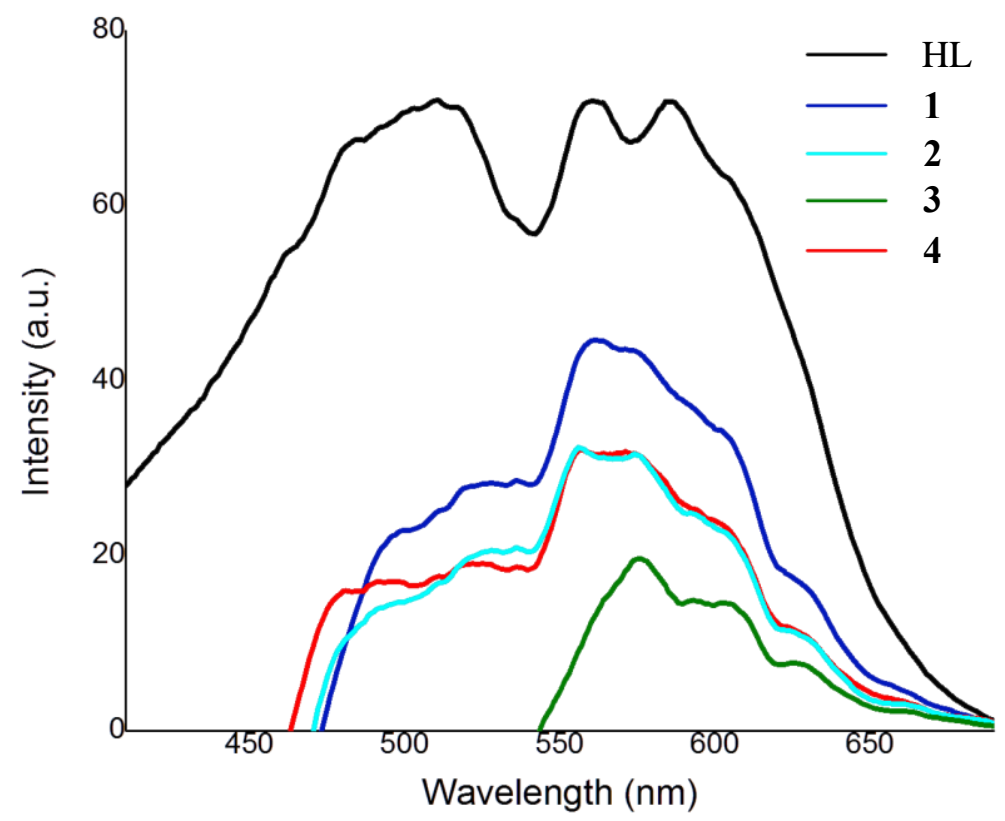

Fig. 7. Solid-state photoluminescence studies at $298 \mathrm{~K}$ with $\lambda_{\mathrm{ex}}=365 \mathrm{~nm}$.

Complexes 1, 2, and $\mathbf{4}$ appear to have very similar spectral lines, and this likely originates in the similarities in their structures: a) they all have two different metal centres in their asymmetric units ( 3 has only one $\mathrm{Cd}(\mathrm{II})$ metal ion), and b) one of the $\mathrm{Cd}(\mathrm{II})$ metal ions is 6coordinate with an approximate octahedral coordination geometry. Even though we cannot directly relate these structural features with the appearance of a plateau in the photoluminescence spectra of 1, 2, and 4 between $\sim 460 \mathrm{~nm}$ and $\sim 550 \mathrm{~nm}$, as well as the very similar relative intensities (20 \pm 7 a.u.), these similarities are nevertheless worth noting. In the case of $\mathbf{3}$, we have matching features with the other samples above $\sim 575 \mathrm{~nm}$, but the drop in intensity make the presence, if any, of a plateau undetectable. Further investigation of these features is beyond the scope of the present work.

\section{Conclusions}

Herein we report a series of $\mathrm{Cd}(\mathrm{II})$ coordination complexes and networks, featuring a pyridine-based tetradentate Sciff base ligand. The different complexes were the result of a systematic study of the anion influence on the resulting materials. The anions used in this study were $\mathrm{CH}_{3} \mathrm{COO}^{-}, \mathrm{N}_{3}^{-}$, and $\mathrm{SCN}^{-}$. These ancillary ligands were proven to play a central role in the self assembly of the resulting structures, due to their variable ability to bridge metal centres. 
$\mathrm{Cd}(\mathrm{II})$ is a versatile metal ion, easily adopting different coordination geometries, and as such this study further demonstrates the capacity of $\mathrm{Cd}(\mathrm{II})$ as a metal node in CPs and/or MOFs. The pyridine-based Schiff base ligand we used in this work constitutes another effective tool in our arsenal toward the synthesis of CPs and MOFs. One very important feature of this ligand is the para-pyridyl group; the latter, together with the $\mathrm{N}_{2} \mathrm{O}$ donor moiety of the ligand backbone make HL a potentially tetradentate ligand system, capable of intermolecular bridging via the pyridyl unit. Finally, this work is part of our ongoing effort to enrich the area of coordination polymers and MOFs with information about the use of ancillary ligands and how they influence the structure of covalently-bonded or supramolecular networks.

\section{Acknowledgements}

We are grateful to the University of Tabriz for the generous financial support of this research. C.L. acknowledges the Cottrell College Science Award by the Research Corporation for Science

Advancement, the Camille and Henry Dreyfus foundation, and the US National Science Foundation (DMR-1429428, DMR-1626332) for support of this work.

\section{References}

1 R. Matsuda, R. Kitaura, S. Kitagawa, Y. Kubota, R.V. Belosludov, T.C. Kobayashi, H. Sakamoto, T. Chiba, M. Takata, Y. Kawazoe, Nature, 436, (2005), 238.

2 R.E. Morris, P.S. Wheatley, Angew. Chem., Int. Ed. 47 (2008), 4966.

3 J.R. Li, X.H. Bu, R.H. Zhang, Inorg. Chem. 43 (2004) 237.

4 a) A.R. Millward, O.M. Yaghi, J. Am. Chem. Soc. 127 (2005), 17998. b) J. M. Hao, B. Y. Yu, K. Van Hecke, G. H. Cui, CrytEngComm. 17 (2015) 2279.

5 a) H. Furukawa, M.A. Miller, O.M. Yaghi, J. Mater. Chem. 17 (2007), 3197. b) P. Zhang, H. Li, G. M. Veith, S. Dai, Adv. Mater. 27 (2015) 234.

6 a) H. Chun, H. Jung, J. Seo, Inorg. Chem. 48 (2009), 2043. b) C. Seidel, C. Lorbeer, J. Cybinska, A. V. Mudring, U. Ruschewitz, Inorg. Chem. 51 (2012) 4679.

7 a) G. Yang, R.G. Raptis, P. Šafár, Cryst. Growth Des. 8 (2008), 981. b) Y. Hasegawa, T. Nakanishi, RSC Adv. 5 (2015) 338. 
8 a) D.L. Long, A.J. Blake, N.R. Champness, C. Wilson, M. Schröder, J. Am. Chem. Soc. 123 (2001), 3401. b) Y. Cong Ou, X. Gao, Y. Zhou, Y. C. Chen, L. F. Wang, J. Z. Wu, M. L. Tong, Cryst. Growth Des. 15 (2015), 966.

9 a) A.Ö. Yazaydin, R.Q. Snurr, T.H. Park, K. Koh, J. Liu, M.D. LeVan, A.I. Benin, P. Jakubczak, M. Lanuza, D.B. Galloway, J.J. Low, R.R. Willis, J. Am. Chem. Soc. 131 (2009), 18198. b) M. Rams, E. V. Peresypkina, V. S. Mironov, W. Wernsdorfer, K. E. Vostrikova, Inorg. Chem. 53 (2014) 10291.

10 a) C. Qin, X.L. Wang, E.B. Wang, Z.M. Su, Inorg. Chem. 44 (2005), 7122. b) Y. Zhao, X. H. Chang, G. Z. Liu, L. F. Ma, L. Y. Wang, Cryst. Growth Des. 16 (2016), 946.

11 a) K.Z. Shao, Y.H. Zhao, X.L. Wang, Y.Q. Lan, D.J. Wang, Z.M. Su, R.S. Wang, Inorg. Chem. 48 (2009), 10. b) L. Bai, P. Wang, P. Bose, P. Li, R. Zou, Y. Zhao, ACS Appl. Mater. Interface. 7 (2015) 5056.

12 a) W.Q. Zou, M.S. Wang, Y. Li, A.Q. Wu, F.K. Zheng, Q.Y. Chen, G.C. Guo, J.S. Huang, Inorg. Chem. 46 (2007), 6852. b) X. Zhang, W. Wang, Z. Hu, G. Wang, K. Uvdal, Coord. Chem. Rev. 284 (2015) 206.

13 D. Venkataraman, S. Lee, J.S. Moore, P. Zhang, K.A. Hirsch, G.B. Gardner, A.C. Covey, C.L. Prentice, Chem. Mater. 8 (1996), 2030.

14 B. Moulton, M.J. Zaworotko, Chem. Rev. 101 (2001), 1629.

15 L. Carlucci, G. Ciani, P. Macchi, D.M. Proserpio, S. Rizzato, Chem. Eur. J. 5 (1999), 237.

16 O.S. Jung, S.H. Park, K.M. Kim, H.G. Jang, Inorg. Chem. 37 (1998), 5781.

17 (a) M. A. Withersby, A. J. Blake, N. R. Champness, P. A. Cooke, P. Hubberstey, W. S. Li, M. Schroder, Inorg. Chem. 38 (1999) 2259. (b) T. L. Hennigar, D. C. MacQuarrie, P. Losier, R. D. Rogers, M. J. Zaworotko, Angew. Chem., Int. Ed. 36 (1997), 972.

18 (a) M. A. Withersby, A. J. Blake, N. R. Champness, P. Hubberstey, W. S. Li, M. Schroder, Angew. Chem., Int. Ed. 36 (1997), 2327. (b) L. Carlucci, G. Ciani, P. Macchi, D. M. Proserpio, S. Rizaato. Chem. Eur. J. 5 (1999), 237.

19 (a) J. R. Black, N. R. Champness, W. Levason, G. Reid, J. Chem. Soc., Chem. Commun. (1995), 1277. (b) J. R. Black, N. R. Champness, W. Levason, G. Reid, J. Chem. Soc. Dalton Trans. (1995), 3439.

20 (a) Y.Q. Huang, Z.L. Sheng, X.Y. Zhou, T.-a. Okamura, Z. Su, J. Fan, W.Y. Sun, J.Q. Yu, N. Ueyama, Cryst. Eng. Comm. 12 (2010), 4328; (b) Y.Q. Huang, Z.L. Sheng, T.-a. Okamura, Y. Wang, X.F. Wang, W.Y. Sun, J.Q. Yu, N. Ueyama, Dalton Trans. (2008), 204.

21 A. Gutiérrez, M.F. Perpiñán, A.E. Sánchez, M.C. Torralba, M.R. Torres, M.P. Pardo, Inorg. Chem. Acta 363 (2010), 2443; (b) A.J. Blake, N.R. Champness, P.A. Cooke, J.E. Nicolso, C. Wilson, J. Chem. Soc. Dalton Trans. (2000), 3811; (c) S. Hu, Z.M. Zhang, Z.S. Meng, Z.J. Lin, M.L. Tong, Cryst. Eng. Comm. 12 (2010), 4378.

22 R. Custelcean, Chem. Soc. Rev. 39 (2010), 3675. 
23 (a) X.R. Meng, X.J. Wu, D.W. Li, H.W. Hong, Y.T. Fan, Polyhedron 29 (2010), 2619;

(b) X.L. Wang, Y.Q. Chen, G.C. Liu, H.Y. Lin, J.X. Zhang, J. Solid State Chem. 182 (2009), 2392; (c) G.C. Xu, Q. Hua, T. Okamura, Z.S. Bai, Y.J. Ding, Y.Q. Huang, G.X. Liu, W.Y. Sun, N. Ueyama, Cryst. Eng. Comm. 11 (2009), 261.

24 (a) R. Vilar, Eur. J. Inorg. Chem. (2008), 357. (b) S.A. Corrales, J.M. Cain, K.A. Uhlig, A.M. Mowson, C. Papatriantafyllopoulou, M.K. Peprah, A. Ozarowski, A.J. Tasiopoulos, G. Christou, M.W. Meisel, C. Lampropoulos, Inorg. Chem. 55 (2016), 1367.

25 S.R. Halper, L. Do, J.R. Stork, S.M. Cohen, J. Am. Chem. Soc. 128 (2006), 15255.

26 R.H. Wang, D.Q. Yuan, F.L. Jiang, L. Han, Y.Q. Gong, M.C. Hong, Cryst. Growth. Des. 6 (2006), 1351.

27 X.J. Zhang, X.P. Zhou, D. Li, Cryst. Growth Des. 6 (2006), 1440.

28 R. Vilar, Angew. Chem., Int. Ed. 42 (2003), 1460.

29 A. A. Khandar, F. A. Afkhami, S. A. Hosseini-Yazdi, J. Lipkowski, W. G. Dougherty, W. S. Kassel, H. R. Prieto, S. G. Granda, J. Inorg. Organomet. Polym. 25 (2015), 860.

30 (a) P. V. Bernhardt, G. J. Wilson, P. C. Sharpe, D. S. Kalinowski, D. R. Richardson, J. Bio. Inorg. Chem. 13 (2008), 107. (b) H. Hosseini-Monfared, R. Bikas, R. Szymczak, P. Aleshkevych, A. M. Owczarzak, M. Kubicki, Polyhedron, 63 (2013), 74. (c) R. Bikas, H. Hosseini-Monfared, M. Siczek, A. Gutierrez, M. S. Krawczyk, T. Lis, Polyhedron, 67 (2014), 396.

31 P. V. Bernhardt, P. Chin, P. C. Sharpe, D. R. Richardson, J. Chem. Soc. Dalton Trans. (2007), 3232.

32 L. K. Thompson, C. J. Matthew, L. Zhao, Z. Xu, D. O. Miller, C. Wilson, M. A. Leech, J. A. K. Howard, S. L. Heath, A. G. Whittaker, R. E. P. Winpenny, J. Solid. State. Chem. 159 (2001), 308.

33 H. Grove, T. L. Kelly, L. K. Thompson, L. Zhao, Z. Xu, T. S. M. Abedin, D. O. Miller, A. E. Goeta, C. Wilson, J. A. K. Howard, Inorg. Chem. 43 (2004), 4278.

34 F.A. Cotton, G. Wilkinson, C.A. Murillo, M. Bochmann, Advanced Inorganic Chemistry, Sixth ed., John Wiley and Sons, New York, 1999.

35 (a) G. B. Li, J. M. Liu, Y. P. Cai, C. Y. Su, Cryst. Growth Des. 11 (2011), 2763; (b) C. P. Li, J. Chen, P. W. Liu, M, Du, Cryst. Eng. Comm. 16 (2014), 6433; (c) A. A. Khandar, F. A. Afkhami, S. A. H. Yazdi, J. M. White, S. Kassel, W. G. Dougherty, J. Lipkowski, D. Van Derveer, G. Giester, F. Costantino, Inorg. Chim. Acta, 427 (2015), 87; (d) C.Q. Wan, H. J. Yan. T. C.W. Mak, Inorg. Chim. Acta, 432 (2015), 13.

36 G. Mahmoudi, A. Morsali, A. D. Hunter, M. Zeller, Cryst. Eng. Comm. 9 (2007), 704.

37 (a) M.R. Maurya, S. Khurana, W. Zhang, D. Rehder, J. Chem. Soc. Dalton Trans. (2002), 3015; (b) L. V. Ababei, A. Kriza, C. Andronescu, A. M. Musuc, J. Therm. Anal. Calorim. 107 (2012), 573.

38 (a) S. Yumnam, L. Rajkumari, J. Chem. Eng. Data, 54 (2009), 28. (b) C. M. Armstrong, P.V. Bernhardt, P. Chin, D. R. Richardson, Eur. J. Inorg. Chem. (2003), 1145; (c) C. B. 
Aakeröy, S. Forbes, J. Desper, Cryst. Eng. Comm. 14 (2012), 2435; (d) Z. He, C. He, E. Q. Gao, Z. M. Wang, X. F. Yang, C. S. Liao, C. H. Yan, Inorg. Chem. 42 (2003), 2206; (e) Y. Y. Zhang, S. X. Liu, Acta Crystallogr. C65 (2009), m269; (f) F. A. Afkhami, A. A. Khandar, G. Mahmoudi, W. Maniukiewicz, J. Lipkowski, J. M. White, R. Waterman, S. Garcia-Granda, E. Zangrando, A. Bauza and A. Frontera, Cryst. Eng. Comm. 18 (2016), 4587. (g) K. A. Abboud, R. C. Palenik, G. J. Palenik, R. M. Wood, Inorg. Chim. Acta, 360 (2007), 3642.

39 (a) G. Mahmoudi, M. S. Gargari, F. A. Afkhami, C. Lampropoulos, M. Abedi, S. A. Corrales, A. K. Khandar, J. Mague, D. Van Derveer, B. K. Ghosh, and A. Masummi, Polyhedron, 93 (2015), 46. (b) A. A. Khandar, B. K. Ghosh, C. Lampropoulos, M. S. Gargari, V. T. Yilmaz, K. Bhar, S. A. Hosseini-Yazdi, J. M. Cain, and G. Mahmoudi, Polyhedron, 85 (2015), 467.

40 G. M. Sheldrick, SHELXTL: Structure Determination Software Suite, Version 6.14, Bruker AXS, Madison, WI, USA, 2003.

41 L. J. Farrugia, J. Appl. Crystallogr. 30 (1997), 565.

42 Mercury 1.4.1, Copyright Cambridge Crystallographic Data Centre, 12 Union Road, Cambridge, CB2 1EZ, UK, 2001-2005. 

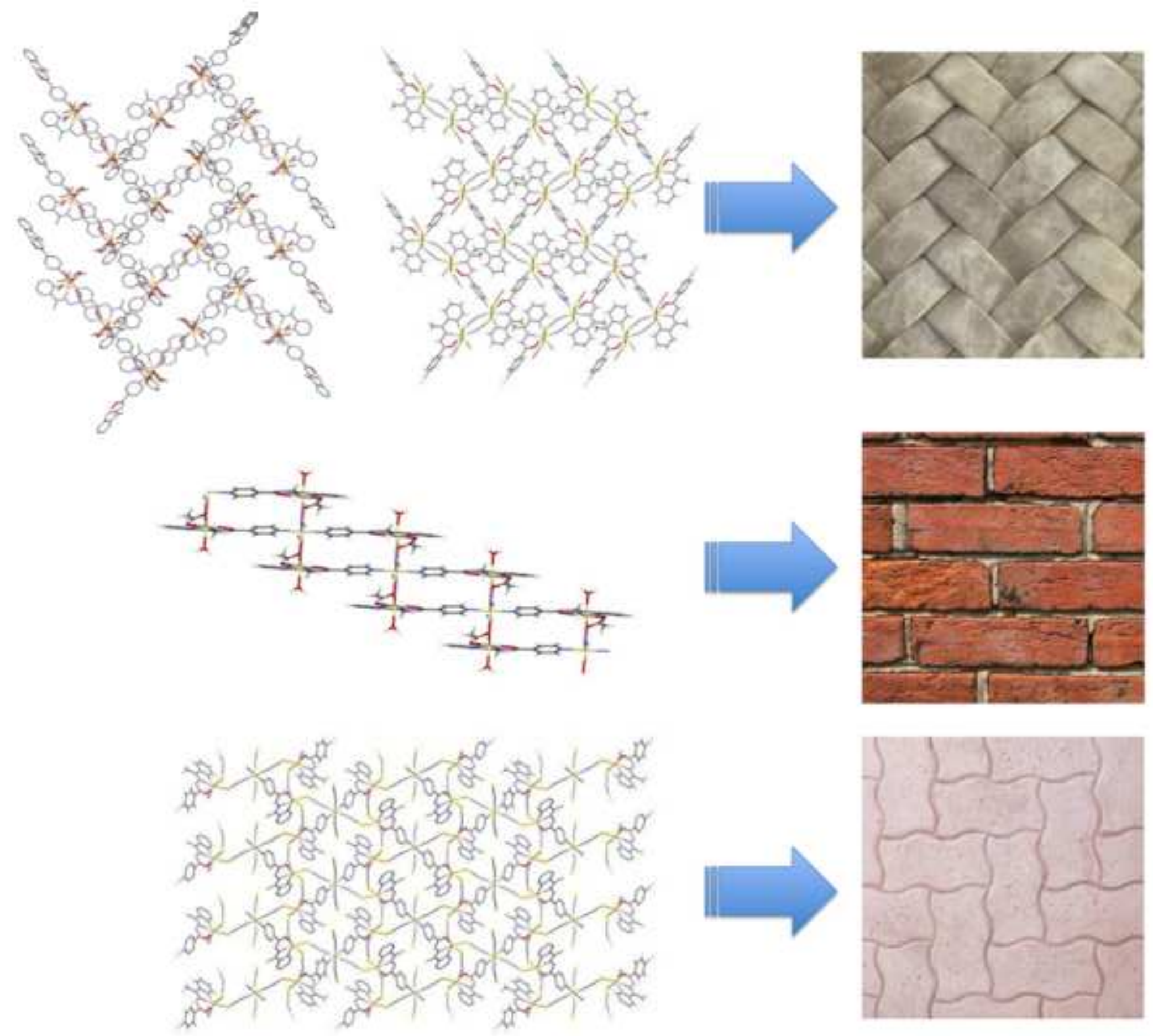
The investigation of 2-acetyl-pyridine-isocotinoylhydrazone in $\mathrm{Cd}(\mathrm{II})$ chemistry is reported. Four different coordination polymers were produced from the anion dependence study. The coordination and bridging ability of the hydrazone ligand is crucial in the assembly of the resulting coordination networks. The chelate/bridging capacity of the ancillary ligands was also found to be a key factor for the structural diversity of the resulting materials. 